\title{
Effectiveness and Implications of Lecture Based Instruction in Maternal and Childcare to Students Social Competency Skills and Community Awareness
}

\author{
Cherry Rose T. Malgapo ${ }^{1} \&$ Nieves T. Adjarani ${ }^{2}$ \\ DepEd Nueva Ecija, Philippines ${ }^{1}$ \\ Manuel V. Gallego Colleges Inc. Foundation, Philippines²
}

\begin{abstract}
Maternal-child care is one of the foundations of primary health care. Nurses' competency skills they have been taught. Community awareness is an important part of preventive healthcare, and nurses must be aware of the factors that impact the health of the community. This study examines the effectiveness of lecture-based instructions in maternal and child care and its implications to students' social competency skills and community awareness in Nursing Colleges in Nueva Ecija, Philippines. The researcher uses survey questionnaire and employed the descriptive design where fifteen (15) nursing students and five (5) teachers were purposively selected. The findings revealed that the weighted mean for the effectiveness of lecture based instruction in maternal and child care is 3.91 with verbal description of "Effective", the effects of lecture based instruction in maternal and childcare to students' social competency skills and community awareness got the weighted mean of 3.87 and interpreted as "very satisfactory" and the effectiveness of actual community-based instruction is very effective with weighted mean of 4.25 and is higher compare to lecture based instruction. The results also revealed that students and teachers were challenged in lecture-based instruction in maternal and chi8ldcare during distance learning. Recommendations for the enhancement of lecture-based instruction in maternal and childcare in social competency skills and community awareness were also made.
\end{abstract}

Keywords: Lecture based instruction, Actual community-based instruction, maternal and child care, social competency skills, community awareness

\section{INTRODUCTION}

Novel Corona Virus (COVID-19) is an infectious disease that is caused by the newly discovered virus severe acute respiratory syndrome coronavirus-2 (SARS- COV-2) as identified by International Committee on Taxonomy of Viruses (ICTV). It was first identified in Wuhan, Hubei China as pneumonia of unknown origin on December 2019.

COVID- 19 disease has caused global pandemic due to the widespread sickness and death. It has changed the lives of individuals and has affected the health systems and economic status of all nations and change the system of education all over the world. This current pandemic brought challenges and difficulties especially to the field of education where there is a closure of educational institutions around the globe. While the country is dealing with the COVID-19 
pandemic, the Commission on Higher Education (CHED) and the Department of Education (DepEd) have both introduced and implemented the versatile distance learning approach. Distan ce learning is a method that enables students to continue their education despite the lockdown an d community quarantine. Educators and students are physically separated in this method, which $i$ $\mathrm{s}$ achieved by the use of technological tools to maintain and provide the education that students need an to facilitate the communications between students and teachers. These adjustments contribute to the uncertainty and different challenges that today's world poses, as well as rising the demands put on institutions and educational systems.

COVID19 has caused educational institutions across the world to close. Mahmood (2020) looked into various instructional methods for online teaching during pandemic. He mentioned that in higher education, instructional strategies may facilitate in the implementation of online teaching. His study develops various online teaching methods that do not compromise student learning which can assist in the development of productive and successful online study sessions. Different ideas for online education in developing countries were also generated in the study. It involves teachers learning vocal functions and maintaining a slow voice and sharing resources prior to the class would also assist in the development of interactive online classes. These techniques are important for improving student learning. It also suggested that CHED should cooperate with the telecommunications industry; this will assist in the solution of Internet-related problems. There are a variety of factors that contribute to the success of remote learning, receiving input from students, as well as having flexible teaching and evaluation policies, are among these factors. The ability to record online lectures and obtain assistance from teaching assistants is also valuable features. These instructional strategies would be essential tool in the delivery of online courses.

Learning by lecture is unavoidable for everybody at some point in their lives, since it is a means of disseminating basic knowledge and, in some cases, the most appropriate teaching process. However, this approach does not allow the learner to consider that this is an important factor. In nursing school, lectures are one of the most popular teaching strategy. Teaching approaches that improve involvement and promote self-directed learning have been shown to be successful in delivering core information and communicating difficult concepts, resulting in increased learning. The implementation of problem-based learning (PBL) in some medical schools kicked off the transformation. In several medical schools, transformation started with the implementation of problem-based learning (PBL); more recently, lectures have been gradually replaced by team-based learning. Students viewed that traditional didactic lecture as the least effective form of teaching, although engaging students actively during lecture time was viewed as a more effective learning tool. Lectures have the benefit of disseminating information to a wide number of students and can be effective in conveying accurate information. As a consequence, lectures can be an important teaching method. (Alaagib et. al, 2019)

Maternal-child care is one of the foundations of primary health care. Preconception health promotion and illness/injury prevention continue during pregnancy, delivery, the postpartum period, and the child rearing period. As a result, lifelong wellness is emphasized in the perinatal and pediatric care spectrum, which has an effect on family health and early childhood growth. Registered nurses (RNs) are required to have the expertise and skills to provide evidence-based nursing to childbearing and child-rearing families in a variety of environments, such as inner city, rural, northern, indigenous, and global populations, in order to improve wellbeing and 
address health inequities. Human reproduction, being a very natural operation, is an environment in which the nurse's skills are vital to a good outcome for both mother and child. Preventive treatment helps a child's health and proper physical, mental, and social growth as he or she develops. The nurse is frequently the health-care professional who interacts most closely with both the mother and the child, and is therefore ideally qualified to detect possible developmental or parent-child interactions issues.(Mckinnon et. al, 2015)

Human reproduction, while being a very natural operation, is an environment in which the nurse's skills are vital to a good outcome for both mother and child. Preventive treatment helps a child's health and proper physical, mental, and social growth as he or she develops. The nurse is frequently the health-care professional who interacts most closely with both the mother and the child, and is therefore ideally qualified to detect possible developmental or parent-child interactions problems. Nurses who specialize in maternal and pediatric care can work in a variety of environments, including their own homes. Nurses in these fields have the ability to establish long-term relationships with their patients.

The world of nursing has been evolving on a daily basis. The challenge for nursing faculty in today's fast-paced, technologically advanced environment is to teach students critical thinking (CT) skills and the ability to perform efficiently and effectively in a variety of circumstances. Because of the continually changing environment of the health-care system, nurses are faced with a variety of complicated practice challenges for which there are no simple answers. In maternal and pediatric nursing, ability and experience are just part of the picture. A nurse's performance would also be aided by such personal characteristics.

The ability to effectively manage social interactions is known as social competence. In other words, social competence is the ability to get along with others, establish and maintain close relationships, and react appropriately in social situations. Social competence is the product of a broad variety of cognitive abilities, emotional processes, behavioral skills, social knowledge, and personal and cultural values linked to interpersonal relationships, given the difficulty of social interactions.

Community awareness is an important part of preventative healthcare, and those in charge of implementing national health policies may want to consider other important factors that influence community health. According to Fooladi, (2015) in her study nurses play a key role on any effective social healthcare initiative, and they play a critical role in the implementation of any universal health plan, whether private or government-funded. The importance of nurses in improving a society's health and well-being is evident, and nurses should take their responsibilities more seriously in order to have a long-term impact on public health.

To this notion, the researcher aimed to determine the effectiveness of Lecture based instructions in maternal and child care and its implications to students' social competency skills and community awareness in Nursing Colleges in Nueva Ecija, Philippines. 


\section{OBJECTIVES OF THE STUDY}

Generally, this study aimed to determine the effectiveness of Lecture based instructions in maternal and child care and its implications to students' social competency skills and community awareness.

This study aimed to answer the following

1. Determine if lecture-based instruction is effective in maternal and childcare of Nursing students

2. Effects of Lecture based instruction in maternal and childcare to students' social competency skills and community awareness

3. Describe the challenges encountered by nursing students and teachers in lecture-based instruction in maternal and childcare

4. Compare the effectiveness of lecture-based instruction through Distance learning and the actual community-based instruction.

\section{RESEARCH METHOD}

The researcher used descriptive research design in this study. It involves fifteen (15) nursing students and five (5) teachers Nursing Colleges in Nueva Ecija, Philippines who were selected using purposive sampling. The questionnaire consisted of Likert scale with verbal description of "Excellent", "Very Satisfactory", "Satisfactory", "Needs Improvement" and "Poor" as choices. The same way to "Very Effective", "Effective", "Moderately Effective", "Slightly Effective", and "Not Effective". The main instrument was distributed through google form.

Range of scores and its verbal interpretation is shown below:

Table 1. Range and Verbal Interpretation Equivalent

\begin{tabular}{|l|l|l|l|}
\hline Point & Range & Verbal Description & Effectiveness Verbal Equivalent \\
\hline 5 & $4.21-5.00$ & Excellent & Very Effective \\
\hline 4 & $3.41-4.20$ & Very Satisfactory & Effective \\
\hline 3 & $2.61-3.40$ & Satisfactory & Moderately effective \\
\hline 2 & $1.81-2.60$ & Needs improvement & Slightly effective \\
\hline 1 & $1.00-1.80$ & Poor & Not effective \\
\hline
\end{tabular}




\section{RESULTS AND DISCUSSION}

1. Effectiveness of lecture-based instruction in maternal and childcare of nursing students in terms of information/ content, alignment to the thrusts or syllabi of the university, relevance to clinical application, utilization of knowledge and understanding of procedures, clarity of information, knowledge of skills and performance ability.

Table 2. Effectiveness of lecture-based instruction in maternal and childcare of Nursing students

\begin{tabular}{|l|c|c|}
\hline Category & Weighted Mean & Verbal Description \\
\hline Information/ Content & 3.15 & Effective \\
\hline $\begin{array}{l}\text { Alignment to the thrusts or } \\
\text { syllabi of the university }\end{array}$ & 4.5 & Eery Effective \\
\hline $\begin{array}{l}\text { Relevance to clinical } \\
\text { application }\end{array}$ & 4.15 & Effective \\
\hline $\begin{array}{l}\text { Utilization of knowledge and } \\
\text { understanding of procedures }\end{array}$ & 4.05 & Effective \\
\hline Clarity of Information & 3.90 & Effective \\
\hline Knowledge of skills & 3.75 & Effective \\
\hline Performance Ability & 3.90 & Effective \\
\hline Overall Weighted Mean & $\mathbf{3 . 9 1}$ & \\
\hline
\end{tabular}

Table 2 shows the summary and tallied results of the survey about the effectiveness of lecture-based instruction in maternal and child care. It shows that the overall weighted mean is 3.91 with verbal description of "Effective". The alignment to the thrusts or syllabi of the university got 4.5 which is considered the highest among others and with verbal description of "Very Effective" and Information/ Content got the lowest weighted mean of 3.15 and interpreted as "Effective".

The results indicate that the lecture-based instruction in maternal and child care is effective in terms of information/ content, relevance to clinical application, utilization of knowledge and understanding of procedures, clarity of information, knowledge of skills and performance ability. The lowest weighted mean for this description is primarily because the maternal and child care focuses more on performance and clinical experience of nursing students, the information or content is not enough compared to the experience from communitybased instruction.

2. Effects of lecture-based instruction in maternal and childcare to student's social competency skills and community awareness in terms of behavior, learning skills, motivation, professional skills, language and communication skills, implementing health initiatives and basic care and safety. 
Table 3. Effects of Lecture based instruction in maternal and childcare to students' social competency skills and community awareness

\begin{tabular}{|l|c|c|}
\hline Category & Weighted Mean & Verbal Description \\
\hline Behavior & 3.3 & Satisfactory \\
\hline Learning skills & 3.15 & Very satisfactory \\
\hline Motivation & 4.55 & Excellent \\
\hline Professional Skills & 2.5 & Needs improvement \\
\hline $\begin{array}{l}\text { Language and Communication } \\
\text { Skills }\end{array}$ & 4.5 & Excellent \\
\hline $\begin{array}{l}\text { Implementing } \\
\text { initiatives }\end{array}$ & 4.5 & Excellent \\
\hline Basic care and Safety & & Very Satisfactory \\
\hline \multicolumn{1}{|c|}{ Total } & $\mathbf{3 . 8 7}$ & \\
\hline
\end{tabular}

Table 3 shows the summary and tallied results of the survey about the effects of Lecture based instruction in maternal and childcare to students' social competency skills and community awareness. It shows that the overall weighted mean is 3.87 with verbal description of "Very Satisfactory". Motivation got 4.55 which is considered the highest among others and with verbal description of "Very Satisfactory" Professional skills got the lowest weighted mean of 2.5 and interpreted as "Needs improvement".

The results indicate that the lecture effects of Lecture based instruction in maternal and childcare to students' social competency skills and community awareness is excellent in terms of motivation, language and communication skills, implementing health initiatives and basic care and safety. Learning skills is very satisfactory and professional skills needs improvement. The lowest weighted mean for this description is primarily because the maternal and child care always has a clinical experience or application which means during distance learning, the nursing students will not be able to apply all the professional skills taught to them due to the situation and lack of resources.

3. Challenges encountered by nursing students and teachers in lecture-based instruction in maternal and childcare during distance learning.

Teachers and even the learners are challenged in lecture-based instruction in maternal and childcare during distance learning perhaps due to the following reasons:

1. Misunderstanding of lessons/ topics

2. Some may have complex activities

3. Less clinical experience

4. Less attention of students during teaching

5. Scarcity of resources needed

4. Effectiveness of lecture-based instruction through distance learning and the actual community based instruction in terms of satisfactory, enjoyable, time efficient, experience, learning objectives awareness, better attention during class, and better academic performance and outcomes. 
Table 4. Effectiveness of lecture-based instruction through Distance learning and the actual community-based instruction

\begin{tabular}{|c|c|c|c|c|}
\hline \multirow[t]{2}{*}{ Category } & \multicolumn{2}{|c|}{ Lecture Based Instruction } & \multicolumn{2}{|c|}{$\begin{array}{l}\text { Actual Community Based } \\
\text { Instruction }\end{array}$} \\
\hline & $\begin{array}{l}\text { Weighted } \\
\text { Mean }\end{array}$ & $\begin{array}{c}\text { Verbal } \\
\text { Description }\end{array}$ & $\begin{array}{l}\text { Weighted } \\
\text { Mean }\end{array}$ & Verbal Description \\
\hline Satisfactory & 3.45 & Effective & 4.45 & Very effective \\
\hline Enjoyable & 3.3 & $\begin{array}{l}\text { Moderately } \\
\text { effective }\end{array}$ & 4.5 & Very effective \\
\hline Time efficient & 4.35 & Very Effective & 3.6 & Effective \\
\hline Experience & 2.6 & Slightly effective & 4.5 & Very effective \\
\hline $\begin{array}{l}\text { Learning } \\
\text { Objectives } \\
\text { Awareness }\end{array}$ & 4.15 & Effective & 4.10 & effective \\
\hline $\begin{array}{l}\text { Better attention } \\
\text { during class }\end{array}$ & 2.55 & Slightly effective & 4.15 & effective \\
\hline $\begin{array}{l}\text { Better academic } \\
\text { performance and } \\
\text { outcomes }\end{array}$ & 3.7 & Effective & 4.45 & Very effective \\
\hline Total & 3.44 & Effective & 4.25 & Very effective \\
\hline
\end{tabular}

Table 4 shows the tallied results of the survey about the effectiveness of lecture-based instruction through Distance learning and the actual community-based instruction. It shows that the overall weighted mean of lecture-based instruction is 3.44 with verbal description of "Effective" and the overall weighted mean of actual based community instruction is 4.25 interpreted as "Very Effective". Lecture based instruction got the lowest mean in terms of experience with 2.6 and interpreted as "slightly effective" and actual community-based instruction got the highest weighted mean of 4.45 in terms of satisfactory with verbal description of "Very Effective".

The results indicate that the actual community-based instruction is more effective compare to lecture-based instruction in maternal and child care of nursing students primarily because nursing students needs to be on actual experience rather than lecture based in maternal and childcare because they need an experience and clinical application. The actual communitybased instruction is more effective in terms of satisfactory, enjoyable, experience, better attention during class, and better academic performance and outcomes while lecture-based instruction is more effective in terms of time efficient and learning objectives awareness. This means that lecture-based instruction in maternal and child care needs to be improve during distance learning. 


\section{CONCLUSION AND RECOMMENDATIONS}

\section{Conclusion}

The following conclusions are drawn:

1. Lecture based instruction is effective in maternal and child care of nursing students with weighted mean of 3.19 and verbal description of 'Effective".

2. There is a significant relationship between lecture-based instruction in maternal and child care of nursing students and their social competency skill and community awareness.

3. Teachers and students were challenged because of misunderstanding of lessons/ topics, complex activities, less clinical experience, less attention and the scarcity.

4. Actual community-based instruction is more effective than lecture based instruction during distance learning.

\section{Recommendations}

1. Teachers may use actual video tutorial of clinical experience in maternal and child care.

2. Students and Teachers may attend seminars and workshops about maternal and childcare to continuously enhance social competency skills and community awareness.

3. More communication between students and teachers

4. Teachers may include activities with fun

5. Enhance giving real life activities and scenarios

6. Use more broad questions and questioning more respondents

\section{REFERENCES}

Berg, G. A. and Simonson, M. (2016) Distance Learning Educatio. Britannica. Retrieved from https://www.britannica.com/topic/distance-learning

Mahmood, S. (2020). Instructional Strategies for Online Teaching in COVID-19 Pandemic. Wiley Periodicals LLC. Retrieved from https://onlinelibrary.wiley.com/doi/10.1002/hbe2.218

Alaagib, N.A., Musa, O.A. and Saeed A.M. (2019). Comparison of the effectiveness of lectures based on problems and traditional lectures in physiology teaching in Sudan. BMC Medical Education. Retrieved from https://bmcmededuc.biomedcentral.com/articles/10.1186/s12909-019$\underline{1799-0}$

Mahmoud A. K. Ph.D. (2011) Critical Thinking Skills of Nursing Students in Lecture-Based Teaching and Case-Based Learning. International Journal for the Scholarship of Teaching and Learning. Retrieved from https://files.eric.ed.gov/fulltext/EJ1136284.pdf 
Abbaszadeh, A., Sabeghi, H., Borhani, F., \& Heydari, A. (2011). A comparative study on effect of e-learning and instructor-led methods on nurses' documentation competency. Iranian journal of nursing and midwifery research. Retrieved from https://www.ncbi.nlm.nih.gov/pmc/articles/PMC3249805/

MacKinnon K, Marcellus L, Rivers J, Gordon C, Ryan M, Butcher D. (2015). Student and educator experiences of maternal-child simulation-based learning: a systematic review of qualitative evidence protocol. JBI Database System Rev Implement. Retrieve from https://pubmed.ncbi.nlm.nih.gov/26447004/

Gwinnett Colleges and Institute (2019). Maternal and Pediatric Care Nursing Skills. Retrieved from https://www.gwinnettcollege.edu/maternal-and-pediatric-care-a-nurses-guide/

Nehrir B, Vanaki Z, Mokhtari Nouri J, Khademolhosseini SM, Ebadi A. (2016). Competency in nursing students: a systematic review. Int J Travel Med Glob Health. Retrieved from http://www.ijtmgh.com/article_33021_12a0e6bc3d69e52799218e3f83250786.pdf

Jamshidi, N., Molazem, Z., Sharif, F., Torabizadeh, C., Kalyani M. N. (2016) The Challenges of Nursing Students in the Clinical Learning Environment: A Qualitative Study. The Scientific World Journal. Retrieved from https://www.hindawi.com/journals/tswj/2016/1846178/

Nehrir, B., Vanaki, Z., Mokhtari J., Khademolhosseini, S. M. and Ebadi A. (2016) Competency in Nursing Students: A Systematic Review. The International Journal of Travel Medicine and Global Health. Retrieved from https://www.researchgate.net/publication/301246932_Competency_in_Nursing_Students_A_Sys tematic_Review

Kirwa, L. and Gakere, Z. (2016). Clinical Skills Competence Of Nursing Students. Lahti University Of Applied Sciences. Retrieved from https://core.ac.uk/download/pdf/38139172.pdf 